DOI: 10.2478 /ausp-2019-0021

\title{
Attila Imre \\ A Logical English Grammar \\ Braşov: Transilvania University Press, 2019
}

\author{
Review by \\ Raluca SINU \\ Transilvania University of Braşov, Romania \\ Department of Theoretical and Applied Linguistics \\ raluca.sinu@unitbv.ro
}

The author of A Logical English Grammar, Attila Imre, opens the introduction to his book by drawing attention to the negative perception that (most) learners have of grammar. He believes that this is not the learners' fault but the result of the faulty approaches found in grammar books, which have alienated students from it, although "the road to effective language use leads through grammar" (p. 21). The author sets out to offer a possible remedy for this situation under the form of a logical - in the sense of simplified and easy to understand - approach to grammar. Despite its all-encompassing title, the volume deals exclusively with the English verb system, and, as mentioned in the Introduction, it is meant to be only the first in a series of works devoted to the grammar of the English language.

Based on his vast teaching experience, the author attempts to synthesize an extensive bibliography, defining and clarifying concepts and, at the same time, emphasizing the way all of them are connected. The result of his endeavour is a monolingual resource, exclusively theoretical, detailing various aspects of the English verb system without resorting to comparisons to other languages. The author lays no claim to a comprehensive approach to the English verb; he even lists some of the aspects missing from the book (e.g. verbal phrases). Neither does he claim to have produced an original work as the originality of the book - by his own admission - lies in "how the information is presented and the accompanying examples to support the theory" (p. 23, emphasis in the original). However, he states clearly that his primary aim was to achieve comprehensibility, to make English grammar accessible to the interested reader. In fact, he believes that the success of his book should be determined by the readers' response to it although the target audience he has in mind is quite varied, including intermediate and advanced students, native and non-native English teachers. 
The volume comprises seven chapters divided into sections and subsections with explicit titles, which make the content of the book clear and easy to follow. The first chapter, "A Logical English Verb System", presents issues related to the structure, the meaning, and the functions of English verbs, classified into: the strong verb of existence, auxiliary verbs, weak verbs, and modal verbs. Section 1.4.2 offers an almost mathematical account of the class of irregular verbs. The 150 irregular verbs selected for discussion are grouped into 16 distinct categories based on the types of irregularities (spelling, pronunciation, etc.) they display and on whether they can have regular forms or not. The classification is also accompanied by an indication of frequency according to a study conducted by Grabowski and Mindt (1995: 5-22).

Chapter 2, "A Logical English Tense System", deals with the various combinations of tense and aspect in English in an attempt "to discuss verb forms, verb phrases and verb meanings 'embedded' in sentences, and how they convey various meanings by themselves or combined with each other" (p. 81). The subsections contain the forms and nuanced descriptions of the uses of each tense as well as their relationship to other tenses, highlighting the (sometimes subtle) differences between various pairs of tenses. For example, Present Continuous is contrasted with Present Simple (see 2.2.4.1), Future Continuous (see 2.10.3.2), and the Going to Future (see 2.13.3.2).

The focus of the third chapter, "Passive Voice", is on the verbal category of voice, more specifically on passive voice in contrast to active voice, following the pattern introduced in the previous chapter, i.e. form (3.2) and use (3.3). In addition, the behaviour of a number of verbs and verbal constructions (e.g. intransitive verbs, ditransitive verbs, pseudo-passive constructions, complex passive constructions, etc.) in the passive voice is also discussed here.

Chapter 4, "Mood", is devoted to another verbal category. The author makes the distinction between finite and non-finite moods; he considers three finite moods, i.e. the indicative, the imperative, and the subjunctive mood, and in this chapter he addresses only the last two. The subjunctive is presented in terms of its uses and types, where some of the types are the result of a combination of meaning and form (e.g. the mandative subjunctive, cf. 4.2.4.1; analytical subjunctive, cf. 4.2.4.2), while others are based strictly on their form (e.g. formulaic subjunctive, cf. 4.2.4.4; were-subjunctive, cf. 4.2.4.5). It is also interesting to note that, although the author acknowledges the existence of the conditional mood, he decides to approach it under the form of conditional sentences in the next chapter. Thus, Chapter 5, "Conditional Sentences", tackles the concept of condition, the conditional connectors, and the types of conditional sentences (type I, type II, type III, zero conditionals, mixed conditionals). Moreover, particular conditional forms are dealt with in detail; the same applies to the specific meanings of conditionals: for example, indirect conditionals, polite conditionals, implicit conditionals, etc. 
The sixth chapter, "Hypothetical Constructions", starts by linking the subjunctive mood and the conditional sentences through the concept of hypotheticality. The chapter focuses on specific verbs and constructions, such as wish, if only, as if/though, what if, suppose/supposing, or it's... time, drawing attention to the fact that the discussion on hypotheticality will be resumed in the last chapter devoted to modal verbs. Chapter 7, "Modality and Modal Verbs", has two main parts: the first one lists the values that modality can take (e.g. obligation, volition, possibility, etc.), while the second one describes 15 modal verbs separately. The author presents the widely-spread idea of considering would/could/should/might as the past counterparts of will/can/shall/may, adding that, in fact, it would be more accurate to refer to the way they reflect remoteness (Lewis 1986), which is not necessarily temporal (cf. 7.3.1), but it can also be psychological or social.

The book also includes a section of conclusions, three appendices devoted to lists of irregular verbs and study boxes for modal verbs, a reference section, and an index. The extensive reference list covers English resources, as well as Romanian and Hungarian ones, ranging from 1948 to 2012 and various online sources. In addition, each chapter ends with a list of references and online sources. The index helps the user locate relevant concepts and topics dealt with in the book.

The theoretical aspects discussed in A Logical English Grammar are supported by examples, drawings, tables, and word clouds. Examples, both the made-up and the authentic ones, play an important part in the book through their impressive number and explanatory function. The made-up examples depict recurrent characters (e.g. Jane Doe, John Doe, the colonel, etc.) and situations (e.g. war, spy activities, family life, school work, etc.), thus contributing to the coherence of the theoretical presentation. The reader becomes accustomed to the universe of the book, whose style is easily recognizable. Some of the made-up examples refer to real people and situations, while many relate to the characters of the animated film Shrek (e.g. Shrek, Fiona, Donkey, etc.) and their actions. The authentic examples come from a variety of sources: films and TV series, e.g. Star Wars (p. 269, 361), Castle (p. 277), Suits (p. 338); lyrics from songs by 2Pac (p. 41), Queen (p. 207), Roxette (p. 266), Nat King Cole (p. 279), Eminem (p. 349), Elvis Presley (p. 92, 315, 317), etc.; famous quotes belonging to Mahatma Gandhi, Plato, Saint Augustin (p. 267), Charles Dickens (p. 294), Henry Ford (p. 317), etc.; literature, e.g. Hamlet by Shakespeare (p. 326), Pride and Prejudice by Jane Austen (p. 331), or Twilight by Erin Hunter (p. 331); other sources such as the motto of the SAS army corps (p. 67), the Constitution of the USA (p. 294), the Miranda Warning (p. 321), or the Bible (p. 358). In addition, the stylistic value of some of the grammatical forms examined is touched on. Thus, a separate subchapter is added in certain cases, illustrating their use in proverbs, sayings, quotes - for example, in Chapter 3, "Proverbs in Passive Voice" (3.9), in Chapter 5, "Conditional Proverbs, Sayings, Quotes" (5.7), 
in Chapter 7, "Can - Quotes and Proverbs" (7.3.4.6), etc. The examples contribute to the relaxed tone of the text, ensuring that students have fun even when they struggle with a serious topic such as English grammar.

At various times throughout the book, the author criticizes the traditional approach and terminology associated with the verb class for its lack of accuracy and thus its limited usefulness for learners of English. Although he reviews the existing terminology, he often provides alternatives to it - for example, numbers for tenses instead of their names or various other abbreviations (most of them included in the section "Abbreviations, Signs and Symbols"). Because of the alternative terminology to which it resorts, the work may at times become demanding on the reader's concentration. However, as stressed by the author, the focus is invariably on the meaning of the different structures analysed and not on their names. In certain cases, even the author admits that the existing approach/terminology should be the starting point in learning or for innovation. For instance, in the case of conditional sentences: "a solid foundation of verb and tense meanings, completed with modal ones takes us further in effectively using conditionals than trying to remember their names and types, although the initial stage starts from identifying them based on forms and types" (p. 259, emphasis added).

Another point worth mentioning is that the author constantly draws readers' attention to debatable grammar issues, e.g. the uncertain status of the be going to future - a form of future or a modal construction (p. 155); the discussion on whether the conditional is a mood or not (p. 205); the controversy over weresubjunctives (p. 222); the fact that "mainstream theory is hard to accept, as it is rather limited and not functional" in the case of conditional sentences (p. 259). This raises their awareness of the fact that grammar is not set in stone, but it changes and evolves just like language itself, and that there are more possible ways of looking at a particular issue.

As access-oriented reference works (cf. Béjoint 1994/2000), grammar books can be read in full or only consulted for the retrieval of specific information. The "linear description" (p. 374) of the English verb system which A Logical English Grammar proposes is coherent and well-organized. Each chapter can stand alone although they are linked through a complex cross-reference system to all the others. However, punctual consultation may, at times, prove more challenging for the reader because of terminological innovations. For instance, the author uses [aiw] instead of be going to - the explanation is introduced in section 2.1.3, but the form also features in the subsequent chapters, where, in the case of a nonlinear reading, it may prove puzzling as its meaning can only be guessed from the examples. The same holds true for I. (verb form), II. (verb form), and III. (verb form). Neither of the above innovations is included in the initial list of abbreviations.

The previously mentioned mathematical approach in the treatment of irregular verbs extends to other aspects of the book as well. For example, in Chapter 2, tenses 
are numbered as an alternative to the traditional terminology. The reference system of the book is also based on numbers. The author states in the "Introduction" that "references are numbered so as not to completely destroy the reading experience" (p. 23). However, as the work is meant for both students and teachers, we believe that exposure to names from the specialized literature may represent an advantage for some and not necessarily hinder the reading process. It could allow the reader to notice at least whether reference is made to English-language resources or Romanian or Hungarian ones and to see the year of publication of the source.

As far as the target audience is concerned, there is ample evidence that the work is meant (primarily, we could argue) for (non-native) students of English. This statement is based on various clues, including recommendations for learning: "A personal recommendation to learn these irregular verbs is to write them on cards with one side containing the three forms (optionally with their pronunciation, possible variants and expressions), while the other side should contain their translation" (p. 40); the choice of casual examples and their high number; the treatment of irregular verbs, where the tables include an empty column for "students to add one or more possible translations" (p. 34); the attention given to summarizing tables (e.g. p. 68, p. 100, p. 177, etc.); comments such as the one concerning stock phrases with if, which "are highly important for exam purposes" (p. 251). The fact that this is a monolingual grammar book makes it accessible to all learners of English irrespective of their mother tongue, to all students who want to clarify their ideas about English grammar and learn more about it. As such, it is a useful pedagogical tool for both teaching and learning and a welcome addition to the repertoire of English grammars.

To conclude, A Logical English Grammar puts forth a matrix for the study of the English verb system. The author has distilled his teaching experience and indepth knowledge of English grammar into a well-structured volume, written in an engaging style. Considering the complexity of the task, Attila Imre's undertaking is worthy of praise because of his sustained efforts to offer a logical approach to the English verb system and is rooted in a detailed survey of the relevant literature in the field and shaped by the author's original take on English grammar.

\section{References}

Béjoint, Henri. 2000 [1994]. Modern Lexicography: An Introduction. Oxford: Oxford University Press.

Grabowski, Eva-Dieter Mindt. 1995. A corpus-based learning list of irregular verbs in English. International Computer Archive of Modern English 19: 5-22.

Lewis, Michael. 1986. The English Verb: An Exploration of Structure and Meaning. Hove: Language Teaching Publications. 